\title{
El Arxiu d'Etnografia i Folklore de Catalunya o la transformación de la investigación etnográfica en Cataluña a principios de siglo
}

La incorporación académica de la Etnología o Antropología Cultural ha sido tardía. Esta circunstancia data tan sólo de 1972, cuando se creó el Departamento de Antropología Cultural en la Universidad de Barcelona bajo la dirección de C. Esteva Fabregat. A pesar de su juventud institucional, nuestra disciplina tiene añejas raíces. Este artículo quiere dar luz sobre una de ellas: el «Arxiu d'Etnografia i Folklore de Catalunya» (AEFC).

Para comprender la génesis y desarrollo de la institución es necesario acercarnos a algunos aspectos de la figura del fundador y director del AEFC, el Dr. Tomàs Carreras i Artau. Fijaremos nuestra atención en sus fuentes formativas, ya que, gracias a ellas, entraremos en contacto con las bases que informaron la creación de la institución.

Carreras i Artau, uno de los grandes olvidados de la historia de nuestra Etnología, se presenta como una figura que reunió en su persona buen número de las corrientes filosóficas, psicológicas, jurídicas y folklóricas de su momento. Las referidas fuentes fueron:

1. La Filosofía del Sentido Común'. Esta corriente filosófica tuvo su auge en Cataluña entre 1847 y 1872. Su representante más señalado fue Xavier Llorens i Barba, aunque el primero que la difundió fue Martí d'Eixalà. Las enseñanzas de Llorens se convirtieron en el aliento vital de buen número de realizaciones de la Cataluña de la segunda mitad del siglo pasado, vg. Jurisprudencia, Folklore.

Si así ocurrió fue por la importancia de sus postulados. Su apelación al método experimental, a la observación, introspección psicológica y tradición y memoria, como medios para averiguar las características de la personalidad individual y colectiva, vino a romper el monopolio de las interpretaciones

1 Ver: Joaquín Carreras ARTAU, «Un maestro barcelonés de Menéndez y Pelayo: Javier Llorens y Barba», Revista de Filosofía, 58-59 (1956), pp. 445-463 y La filosofía universitaria en Cataluña durante el segundo tercio del siglo XIX (Barcelona: CSIC, 1964). 
de carácter metafísico, hasta entonces imperantes, como bien ha señalado D. Núñez Ruiz ².

A pesar de que esta filosofía desapareció del panorama académico barcelonés a la muerte de Llorens (1872), sus principios continuaron explicándose en el ámbito de la jurisprudencia catalana, espacio donde Carreras entró en contacto con ella, llegando a convertirse en un ferviente admirador y estudioso de Llorens, hasta el punto de que se puede afirmar que el AEFC fue un reflejo directo de las posturas defendidas por éste.

2. La Escuela Jurídica e Histórica Catalana ${ }^{3}$. A lo largo del s. XIX, en Cataluña se formó y desarrolló la Escuela Jurídica Catalana, herencia directa de las realizaciones de Savigny. Como afirma el prof. Lalinde Abadía, fue Cataluña el lugar de España donde los predicamentos del jurista germano recalaron con más fuerza. En buena medida, ello respondió a la defensa que realizaba de los caracteres propios de cada pueblo. La clase jurídica catalana, así como la política, necesitadas de un respaldo frente a las reformas administrativas y a los aires librecambistas del momento, se identificó con los postulados de la Escuela Histórica, ya que ello le dio pie para luchar a ultranza por el proteccionismo económico. De esta forma, buen número de abogados y notarios se lanzaron a la recopilación de usos y costumbres propios. Ejemplos se podrían citar muchos, mas recordemos a V. Santamarina y F. Maspons i Labrós.

3. La Renaixença y el Folklore Catalán del s. XIX. Cataluña tuvo una evolución diferenciada, en especial en la economía, del resto de España durante la centuria pasada. En el orden de la cultura y de la literatura, tal desarrollo quedó reflejado en el movimiento de la Renaixença, el cual se convirtió en el artífice del resurgimiento de la conciencia nacional catalana.

El Folklore contribuyó de forma poderosa a todo ello. Desde las publicaciones de Piferrer o las de M. Milá i Fontanals sobre Romancerillos (1853 y 1882), en Cataluña surgió un movimiento para recuperar sus costumbres y tradiciones específicas. El nacionalismo marcó el desarrollo del Folklore, hasta tal punto que se puede decir que ha sido uno de sus motores, aunque también es necesario señalar que coartó en algún momento su evolución.

2 La mentalidad positiva en España. Desarrollo y crisis (Madrid: Ed. Túcar, 1975), p. 119.

3 Sobre la Escuela Jurídica Catalana, véase: Manuel DURÁN y BAS, Escritos del Excmo. Sr. D. Manuel Durán y Bas. Primera Serie. Estudios Jurídicos (Barcelona: Lib. del Editor D. Juan Oliveres, 1888); J. M.' FONT I RuUs, «El pensament juridic», F. Soldevilla (ed.), Un segle de vida catalana (Barcelona: Ed. Aedos, 1964), I, pp. 42142 y II, pp. 1180-1185; A. E. PÉREZ LUÑo, «Experiencia histórica y experiencia jurídica en Durán y Bas», Llibre del II Congrés Jurídic Català (Barcelona: Fund. Segundo Congreso Jurídico Catalán, 1972), pp. 143-149. 
Estas fueron las tres fuentes doctrinales básicas de Carreras. A ellas deben añadirse:

La crisis de 1898. A raíz de ella, la burguesía catalana consideró que, como grupo socioeconómico, era el ejemplo a seguir para salvar a España del «caos finisecular». La Mancomunitat de Catalunya así como el movimiento del Noucentisme fueron la traducción pragmática de esta situación. Ambos quisieron modernizar Cataluña y de esta forma servir de modelo al resto del Estado.

Carreras vivió íntimamente este momento de la historia catalana, hasta el punto que el Arxiu d'Etnografia $i$ Folklore de Catalunya se presenta hoy como aquella institución, de carácter antropológico, que tradujo a realidades los ideales regeneracionistas y «noucentistes», como ya señalaremos.

El positivismo. Es conocida la importancia de este movimiento desde su llegada a España. En Cataluña su implantación fue difícil debido a su vinculación al republicanismo de fines de siglo, fuerza minoritaria en el espectro político catalán. Así, las obras de Littré o Lombroso, la acción de Pompeyo Gener o Pedro Estasen, declarados positivistas, no tuvieron gran repercusión, aunque todavía hoy no se ha investigado con suficiente profundidad tal cuestión.

Carreras aceptó en alto grado los presupuestos positivistas, ya sea a través de sus lecturas de Lombroso, como queda reflejado en su escrito de 1897 Un caso jurídico-antropológico, o bien a través de sus maestros madrileños: F. Giner de los Ríos y N. Salmerón, con los que trabó amistad durante el curso 1901-1902, año en que se trasladó a Madrid para realizar el doctorado de las especialidades de Derecho y Filosofía y Letras.

En forma de resumen, señalemos todas estas influencias:

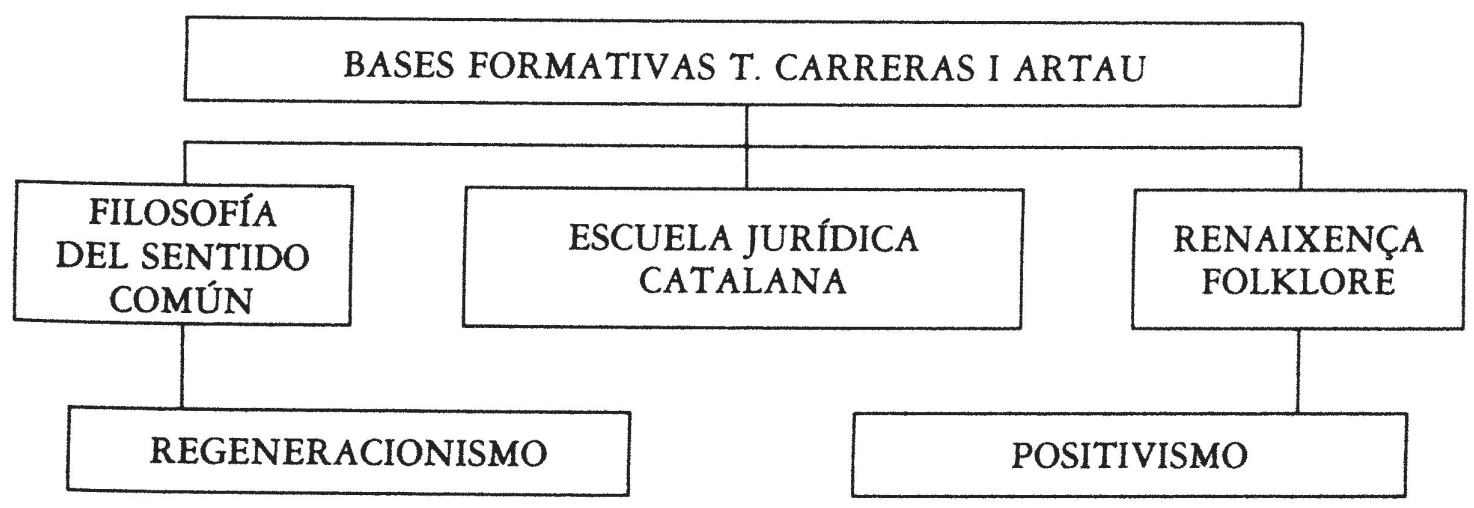

De hecho, todos estos elementos son los que informaron la creación del AEFC. Por ejemplo, la divisa de la institución fue la máxima socrática, adoptada por Llorens i Barba, nosce te ipsum. 
Después de un análisis global de todos ellos, se puede decir que la institución fue fruto de dos transformaciones que se dieron en el panorama finisecular español y catalán.

La primera, cientifica, sería aquella que afectaría al cambio que se produjo en algunos ámbitos de la ciencia española, sobre todo, los referidos a la Psicología y al Folklore y Etnografía, que fueron los que influyeron de forma directa al $A E F C$. La segunda, politico-cultural, hace referencia a los cambios que Cataluña y España vivieron a partir de 1898. Veamos cada una de ellas.

Respecto a la científica hay que señalar, en primer lugar, los aspectos referidos a la Psicología. Con posterioridad se verá el por qué de su importancia en el ámbito del AEFC. La segunda mitad del siglo XIX asistió al cambio en el modo de interpretar e investigar en Psicología. Ésta, hasta este momento, había tenido como punto central el análisis de los estados de conciencia y el discernimiento de las facultades mentales. La metafísica y la filosofía jugaban un importante papel en ella.

A partir de las investigaciones de $\mathbb{W}$. Wundt, la Psicología empezó a abandonar estos terrenos para adentrarse en el camino de la experimentación. Tales cambios también se vivieron en nuestro país, por ejemplo, con la acción de L. Simarro o con la publicación de las Lecciones Sumarias de Psicología de F. Giner de los Ríos ${ }^{4}$.

Wundt no sólo aportó esta perspectiva experimental para la investigación. Propugnó una segunda vía de indagación psicológica, la centrada en las poblaciones: la Völkerpsychologie o Psicología de los Pueblos, que enlazó con los planteamientos de Lazarus y Steinthal. Con el paso del tiempo, ésta murió mientras la experimental triunfó s.

Como investigador preocupado por el conocimiento de los rasgos psicológicos más característicos del pueblo español, Carreras echó mano de ambas corrientes, incorporando claramente el experimentalismo wundtiano a sus estudios así como los principios respecto al conocimiento del psiquismo colectivo. Su vinculación a los presupuestos de Wundt fue tal que, al igual que éste, Carreras planteó que uno de los fines de sus trabajos era elaborar una teoria sobre la gènesi i desenrotllament de la cultura ${ }^{6}$.

4 Ver E. Lafuente, «Los orígenes de la Psicología científica en España: Las «Lecciones sumarias de Psicología» de Giner de los Ríos», Investigaciones Psicológicas, 4 (1987), pp. 165-187.

5 Sobre el particular, véase E. G. BoRING, «W. Wundt», Enciclopedia de las Ciencias Sociales (Madrid: Ed. Aguilar, 1977), X, pp. 764-768.

6 T. Carreras I Artau, «Estudis de Psicologia Étnica. La Mentalitat Primitiva», Anwari de la Societat Catalana de Filosofia, I (1923), p. 227. 
Respecto al ámbito del Folklore y de la Etnografia, indicar que el AEFC fue fruto de la transformación que en las primeras décadas de nuestro siglo se dio en estos campos en España y Cataluña. Piénsese tan sólo en la Encuesta del Ateneo de Madrid (1901) o el curso de Etnografía que Hoyos y Aranzadi impartieron en esta institución en 1915.

La investigación antropológica catalana decimonónica quedó caracterizada por dos modos de hacer: los por mí denominados modelos naturalista $y$ folklorista. El primero abarcó las distintas realizaciones procedentes del ámbito de la sociología positivista (los ya citados Gener, Estasen o el jurista Pella y Forgas) y las del mundo médico (por ej., Letamendi, Comenge o Valentí Vivó). Debido al escaso eco de las propuestas de carácter naturalista y positivista, fue el segundo modelo, el folklorista, el que más arraigó.

Este modelo estuvo hondamente influido por el Romanticismo, en su traducción catalana, la Renaixença: el rescate y salvación de los valores patrios fue la clave de los trabajos. Nacionalismo y recuperación de la identidad propia se convirtieron en estímulo permanente para muchos folkloristas. De alguna manera, lo ocurrido en Cataluña puede asimilarse a lo sucedido en otros países europeos, caso, por ejemplo, de Finlandia con el movimiento de estudiosos del Kalevala.

El AEFC fue tan sólo una manifestación del rechazo de los estudiosos e intelectuales catalanes del «Novecientos» hacia las formas de hacer de la centuria pasada. Si en el Folklore del s. XIX la recopilación se convirtió en método y fin de los trabajos, en las primeras décadas de nuestro siglo la investigación se vio notablemente ampliada, de tal forma que ya apareció teóricamente orientada gracias a la incorporación del historicismo cultural, la investigación arqueológica, la sistematización de la recopilación. Hasta tal punto fue así que el AEFC, como un apéndice del Noucentisme catalán, llegó a crear una teoría propia para sustentar sus investigaciones, la Psicoetnografía.

La segunda transformación de la Cataluña de las primeras décadas de nuestro siglo fue la politico-cultural. Como ya hemos apuntado, a partir de la crisis de 1898, el regionalismo se convirtió en la fuerza política más importante de Cataluña. Ello culminó en la creación de la Lliga Regionalista, formación política nacionalista de carácter conservador, liderada por Enric Prat de la Riba. La Lliga fue dominando, poco a poco, los distintos órganos de poder catalanes. Ello hizo que en 1906 Prat de la Riba accediese al gobierno de la Diputación de Barcelona. Este ascenso de la burguesía catalana al poder se vio coronado con la creación de la Mancomunitat de $\mathrm{Ca}$ talunya en 1914. Estas circunstancias comportaron que las tareas científicas 
tuvieran nuevos apoyos '. Así, cuando en 1906 se creó el Institut d'Estudis Catalans, cuya función fue incentivar la investigación científica y cultural, Prat de la Riba señaló en el dictamen de creación:

Por eso ha llegado la hora de que la Diputación (de Barcelona) tome la iniciativa para fundar aquí centros de estudios científicos, concretamente especializados y destinados, más que a la enseñanza, a producir ciencia y facilitar las investigaciones, para saber directamente lo que tenemos de propio y no tener que aprender de los extranjeros lo que han estudiado en nuestra casa ${ }^{8}$.

Todo este movimiento político estuvo arropado por el Noucentisme, hasta el punto que uno y otro se confundieron. Éste abarcó no sólo el campo de la creación artística sino también el de la investigación científica, por ejemplo, la Societat Catalana de Biologia, la de Filosofia o el Servei de Investigacions Arqueològiques. Fueron varios los vectores que guiaron al Noucentisme, pero uno tuvo una especial importancia: el discernimiento de los orígenes étnicos, lingüísticos, antropológicos y arqueológicos de la nación catalana. El fin era presentar la «diferencialidad» del pueblo catalán. De esta forma, al unísono que nació el AEFC lo hicieron otras ciencias, de carácter antropológico: Antropología Física, Geografía Lingüística y Prehistoria y Arqueología.

La unanimidad de criterios y la estrecha relación que se estableció entre ellas, hicieron que se formase la Associació Catalana d'Antropologia, Etnologia i Prehistòria (1922-1927) '.

Tanto el AEFC como estas disciplinas colaboraron de forma importante al logro de los objetivos que el Noucentisme y la Mancomunitat de Catalunya se habían fijado: la peculiaridad histórica y cultural catalana.

De esta forma, cuando Bosch Gimpera pregonó la necesidad de incrementar la investigación arqueológica y prehistórica en Cataluña, o Griera realizó los Atlas Lingüísticos, la Mancomunitat apoyó de forma decidida tales acciones.

Igual ocurrió con el AEFC, que, como ya se señaló, fue una creación plenamente integrada en su tiempo y en su espacio, tanto catalán como

7 Ver A. Roca Rosell, «Ciencia y sociedad en la época de la Mancomunitat de Catalunya (1914-1923)», J. M. SÁNCHEZ RON (coord.), Ciencia y sociedad en España: de la Ilustración a la Guerra Civil (Madrid: Eds. Arquero/CSIC, 1988), pp. 223-252.

8 Institut d'Estudis Catalans, Prat de la Riba. Propulsor de la llengua i cultura (Barcelona, 1974), p. 72.

9 Véase al respecto, L. Pericot Garcia, «Un episodio en la Historia de la Etnología en España. L'Associació Catalana d'Antropologia, Etnologia i Prehistòria», Revista de la Universidad Complutense, 98 (1975), pp. 15-21. 
español. Fue obra tanto regeneracionista como noucentista. Así, de la primera, estas palabras de Carreras sobre el denominado "problema hispano», resumen de las repercusiones de la crisis de 1898 , son sumamente aclaratorias:

[...] la honda preocupación por el problema hispano por antonomasia es, a saber, el problema que versa sobre la reconstitución espiritual de España: problema de orígenes, de entraña viva, de concreción del ideal colectivo, de revelación y ponderación de aptitudes diversas dentro de la gran comunidad ibérica. Problema de raza, en una palabra, que no hay que confundir con ninguno de los conflictos accidentales y casi siempre pasajeros de la Política y sus partidos organizados ${ }^{10}$.

Respecto al Noucentisme, hay que recordar que uno de sus signos de identificación más señalados fue su declarada fe en el mediterranismo y en el clasicismo. Emparentarse con la cultura clásica significaba dotar a Cataluña de raíces sólidas, profundas. Estos ideales aparecieron. en la institución. Cuando Batista i Roca, secretario de ella, escribió a Carreras i Artau desde Oxford comentándole sus visitas a los museos etnográficos ingleses y pensando en el futuro Museo de Etnografía de Cataluña, señaló:

Com a programa màxim y ideal, hauria de fer-se l'estudi de la cultura popular del Mediterrà occidental. Vaig quedar molt sorprés de veure q. el Dr. Haddon coincidia ab aquesta idea y em recomenava fer a Barcelona un gran Museu de la Cultura Mediterrànea. Realment no hi pot haver imperialisme més bell q. aquest q. pera l'estudi de la cultura mediterrànea, mare de totes les altres, fos necessari anar a Barcelona! ${ }^{11}$.

El AEFC nació en 1915 aunque se puede decir que su auténtico arranque fue en 1912, cuando Carreras Artau consiguió la Cátedra de Ética de la Universidad de Barcelona. A partir de este logro, Carreras se lanzó a la consecución de unos objetivos que había ido diseñando desde que finalizó sus estudios universitarios en 1902. Diversas publicaciones (a destacar la de 1905, La Filosofía del Derecho en el Quijote ${ }^{12}$ ), conferencias, cursos,

10 T. Carreras i Artau, Ética hispana (Gerona, 1912), pp. 7-8.

11 J. M. Batista i Roca a T. Carreras i Artau, Exeter College, Oxford, 8-11920. Archivo AEFC (Institució «Milà i Fontanals», CSIC, Barcelona). La transcripción es fidedigna al texto original, no ateniéndose a la normativa actual de la lengua catalana.

12 M. Menéndez Pelayo dijo de ella (comunicación a T. Carreras Artau, 18 de junio de 1905. Archivo AEFC): «Debe Vd. perseverar en tal género de trabajos. Hechos con la conciencia y severidad de método q. el presente revela, y ampliando cada vez más la investigación, ya en las fuentes filosóficas-jurídicas, ya en las puramente literarias de nuestra edad de oro, llegaremos algún día á tener la historia de las ideas q. sobre el derecho profesaron nuestros antepasados y q. virilmente llevaron a la práctica.» 
participación en congresos, prepararon la acción que a partir de 1912 desarrolló, materializada ese año en la creación del Archivo de Psicología y Ética Hispanas, que tuvo como fin investigar las manifestaciones psicológicas y éticas colectivas.

Este archivo dio paso en 1915 al de Etnografía y Folklore, que se hizo eco tanto de los presupuestos psicologistas de Wundt, del experimentalismo de Giner de los Ríos, de los métodos de observación proclamados por Llorens i Barba, de las enseñanzas de Joaquín Costa ${ }^{13}$, así como de la tradición jurídica, filosófica y folklórica catalana. Respecto a este último aspecto, hay que decir que a pesar de que el $A E F C$ fue uno de los exponentes de este cambio científico, no por ello dejó de lado el mundo del Folklore «renaixentista». Todo lo contrario. Ya E. D'Ors, el máximo «verbalizador» del Noucentisme, había proclamado la necesidad de mantener los añejos Jocs Florals «renaixentistas» aunque con nueva función. De la misma forma, Carreras, Aranzadi y Batista, los otros dos pilares del AEFC, fueron conscientes del valor de los folkloristas para los fines que buscaban. Se recurrió a ellos, alcanzando tal éxito su llamada que en el momento de más auge de la entidad se llegó a contar con cerca de cuatrocientos colaboradores.

El AEFC también se nutrió de la teoría etnológica europea del momento. Destacan, entre otras, las teorías de Lévy-Bruhl, el historicismo cultural centroeuropeo, así como la etnología jurídica de Post ${ }^{14}$ o los trabajos que llevaban a cabo algunos antropólogos ingleses (Marett, Haddon, Rivers) por discernir las relaciones entre cultura/sociedad y personalidad ${ }^{15}$.

Antes de entrar en una pormenorización de lo que fue la institución, creemos interesante reseñar los comentarios de dos de los maestros de la Antropología Española, D. Luis de Hoyos Sáinz y D. José Miguel de Barandiarán, respecto a la obra del AEFC. El primero, al referirse a las propuestas formuladas en el Congreso de Artes Populares de Viena (1928) sobre la necesidad de la creación de archivos folklóricos dijo:

Justo es destacar que antes de las propuestas internacionales, pues data de 1913, funciona en la Universidad de Barcelona el Arxiu d'Etnografía i Folklore

$13 \mathrm{~J}$. Costa fue una de las figuras señeras en la acción de Carreras y del AEFC, hasta el punto que se convirtió en guía de los estudios de la institución. Todo ello se refleja en la conferencia de T. CARRERAS I ARTAU, «Joaquim Costa i els estudis consuetudinaris a Espanya», Estudis $i$ Materials, II (1918), pp. 89-148.

14 La vinculación con ella se refleja en el artículo de T. CARreras I ARTAU, «Una institució per a la recerca del nostre Dret Consuetudinari», Revista Jurídica de Cataluña, XXVI (1920), pp. 57-66.

is Sobre el particular, P. Mercier, Historia de la Antropologia (Barcelona: Península, 1975), p. 72. 
de Catalunya, fundado por el Catedrático señor Carreras Artau, como división del trabajo del Arxiu de Psicologia i Ética hispanes. Desde 1916 publicó los cuadernos que con el título de Estudis i Materials recogen todas las actividades internas de la cátedra, seminario y laboratorios, y las externas de los cooperadores que privadamente trabajan, principalmente en Cataluña; publicaba cuestionarios, organizaba exposiciones fotográficas y redactaba planes concretos para quienes los solicitasen como guías de recolección e investigación folklóricas ${ }^{16}$.

D. J. M. de Barandiarán, en carta dirigida a Carreras fechada el 21 de septiembre de 1920 (Archivo AEFC), señaló (hablando de Estudis i Materials):

Los he leído todos con sumo interés, y he podido apreciar algo de lo mucho que trabajan Uds. en su hermoso país. Han hecho mucho Uds.: ¡Cuánto nos falta a nosotros para llegar en el País Vasco a lo que Uds. han logrado en ese! Verdad es que aquí tenemos un museo etnográfico y otro que ya se está formando; pero en Folklore se ha trabajado muy poco y las colecciones son pobrísimas [...] D. Telesforo de Aranzadi me dijo que Uds. han organizado centros de investigación en los Seminarios de ahí. ¿Podría Ud. avisarme en qué forma lo han hecho? Le agradecería mucho si me enterara de esto, para que podamos hacer aquí una cosa análoga.

El AEFC tuvo como principales responsables a T. Carreras i Artau, T. de Aranzadi y J. M. ${ }^{a}$ Batista i Roca. Cada uno de ellos aportó su experiencia y su ilusión al proyecto. Dejando de lado aquí a Carreras, hay que señalar que Aranzadi puso al servicio de la empresa su saber y su profunda profesionalidad en la investigación, así como su prestigio personal. Sus aportaciones concretas se concentran en tres ámbitos: Antropología física, estudios de cultura material en relación con la Filología (siguiendo el modelo del Wörten und Sachen) y museografía etnográfica. Respecto a Batista i Roca, en aras de la justicia, debe decirse que buena parte de lo que fue la entidad es obra suya ya que durante más de ocho años trabajó denodadamente por ella. Hasta tal punto se entregó al estudio e investigación etnológicas que en 1920 obtuvo el Diploma de Antropología en la Universidad de Oxford.

Este hecho es indicativo de la acción que en el seno de la institución se desarrolló. Sus actividades, junto a las de otras disciplinas próximas, comportaron un cambio sustancial en la forma de concebir y hacer Folklore y Etnografía en Cataluña. Fue tal el cambio que en este momento surgieron ya las dos líneas de investigación que se han dado en Cataluña desde entonces: la centrada en la cultura tradicional, que podríamos denominar Folk-

16 L. de Hoyos Ś́inz y N. de Hoyos SANCHO, Manual de Folklore (Madrid: Istmo, 1985), p. 77. 
lore (siendo representantes Joan Amades, R. Violant, ...) y la que tenía su punto de mira en el estudio del hombre de forma más total, la Etnológica, herencia directa de los trabajos de Batista i Roca, Bosch Gimpera, los hermanos Serra Ràfols, Pericot, y cuyo continuador, después de la guerra civil, ha sido A. Panyella.

Cualquier transformación o revolución científica no consiste tan sólo en crear una forma metodológica de trabajo, con una mayor rigidez y sistematización en la recogida e interpretación de datos, sino que también comporta la creación de nuevos conceptos y de un aparato teórico que sostenga el nuevo edificio. Este principio de la Historia de la Ciencia se cumplió en este caso, yà que el AEFC, además de crear un nuevo estilo de trabajo, articuló una teoría para dar fin y cohesión a sus estudios: la Psicoetnografía.

Centrémonos ahora en las cuestiones referidas a la metodología y a la teoría de la Psicoetnografía. Respecto al primer tema, el AEFC rompió de forma sustancial con las formas que hasta entonces se habían dado en el mundo del Folklore catalán. El mismo Carreras ya lo proclamó cuando dijo:

En son primer període, que podriem anomenar sentimental, el conreu del Folklore a Catalunya fou abans que tot un estimulant del caliu patriòtic. Temperaments investigadors de primera força es llençaren a les recerques folklòriques, més amb l'esperit abrandat de poetes enamorats de la terra que armats amb la disciplina severa del sistematisador [...] els estudis folklòrics mereixen avui a Catalunya, una altre consideració molt més complexa que la predominant filològico-literària. Per a nosaltres el Folklore es objecte adequat de ciència: veritable substratum de raça, constitueix un factor indispensable per a l'estudi de la psicologia comparada del poble català en ses relacions amb els demés pobles hispans i amb el procés general de la civilisació i la cultura ${ }^{17}$.

Positivismo y naturalismo fueron las claves de las acciones de la entidad. De esta forma, J. Oliver Castañer, colaborador del AEFC, señaló:

El Folklore es pues una ciencia compleja, no un arte. Por eso no precisa que el folklorista sea artista o literato, sino psicólogo y naturalista; he aquí por qué más bien necesita del fonógrafo y del Kodak que del cincel y de retoricismos ${ }^{18}$.

Por su parte, Carreras dejó escrito:

17 T. Carreras i ARTAU, «Dues paraules sobre el projectat Museu Etnogràfic de Catalunya», Estudis i Materials, II (1918), p. 30.

18 J. Oliver Castañer, carta a T. Carreras Artau, Barcelona, 24-12-1916. Archivo AEFC. 


\section{ARXIU D'ETNOGRAFIA I FOLKLORE DE CATALUNYA \\ UNIVERSITAT DE BARCELONA}

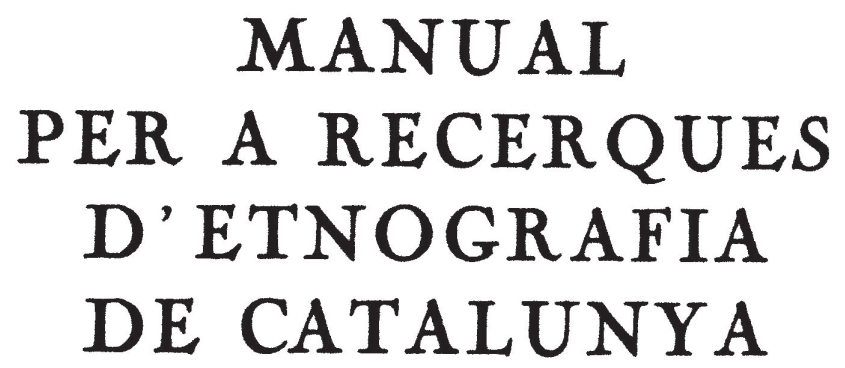

BARCELONA

MCMXXII

Fig.-1. Portada del Manual per a recerques d'Etnografia de Catalunya (Barcelona, 1922). 
En la descripció cal atenir-se estrictament a la veritat, sense retocs ni arranjaments, contràriament a ço que sol fer el literat, el qual persegueix, abans que tot, un efecte artístic ${ }^{19}$.

Tal actitud de trabajo ya se vio reflejada en algunas de las indicaciones que aparecieron en los cuestionarios que la entidad editó, los cuales tenían como objetivo la recopilación, de forma sistemática, del mayor número de rasgos posibles de la cultura tradicional catalana e hispana.

Estos esfuerzos por sistematizar el trabajo etnográfico vieron su culminación cuando, en 1922, el AEFC publicó el Manual per Recerques d'Etnografia de Catalunya. A pesar de que distintos autores ya habían señalado la necesidad de establecer normas, esta obra fue la primera que en Cataluña (y no tengo referencia de otra igual en España) se publicó con fines clara y exclusivamente metodológicos, siendo a nivel europeo, también una de las primeras que se realizó con tal objetivo. Con anterioridad ya se habían publicado cuestionarios con indicaciones metodológicas (vg. Ch. S. Burne, 1914, Handbook of Folklore o los escandinavos), pero no con la perspectiva integral (Etnografía, Folklore, Antropología física, Museografía y Fotografía etnológica) con que el AEFC lo hizo en el Manual. De esta forma, se puede decir que éste fue una de las más altas expresiones de los nuevos visos que adquirió la investigación etnológica durante las primeras décadas de nuestro siglo ${ }^{20}$.

Esta reforma metodológica estuvo emparentada con la que por aquel entonces se estaba empezando a producir en la Etnología mundial. En los años veinte el «modo de etnografiar» inició su transformación, hasta el punto que se planteó la necesidad de una estancia prolongada en las poblaciones, el estudio intensivo de un área o el conocimiento de la lengua indígena. En este momento, el «coleccionar para explicar» dejó de ser prioritario. Hasta tal punto el AEFC enlazó con la nueva situación que algunos

19 T. CARreras I ARTAU, «Psicologia del poble català», Manual per recerques d'Etnografia de Catalunya (Barcelona: AEFC, 1922), p. 63.

20 Las palabras de L. Pericot cuando realizó un análisis del Manual son ilustrativas al máximo de esta situación: "L'estat en que es troben els estudis etnogràfics a Catalunya, fa necessari el dotar al recercador d'un utillatge adequat per a que sos treballs de recerca siguin fets sistemàticament $\mathrm{i}$ amb l'esperit crític que convé a materials que després han d'ésser elaborats científicament. Aquesta finalitat és la perseguida amb la publicació d'aquest Manual, de petit tamany per a ésser fàcilment portat en excursions [...] [el Manual] mostra la vasta extensió en què poden moure's les recerques etnogràfiques més enllà dels reculls de cançons, rondalles, proverbis, etc., que fins ara coinstituîen la major part de la bibliografia folklòrica catalana.» L. PERICOT GARCiA, «Manual per Recerques d'Etnografia de Catalunyan, Bulletí de l'Associació Catalana d'Antropologia, Etnologia i Prebistòria, I (1923), pp. 199-201. 


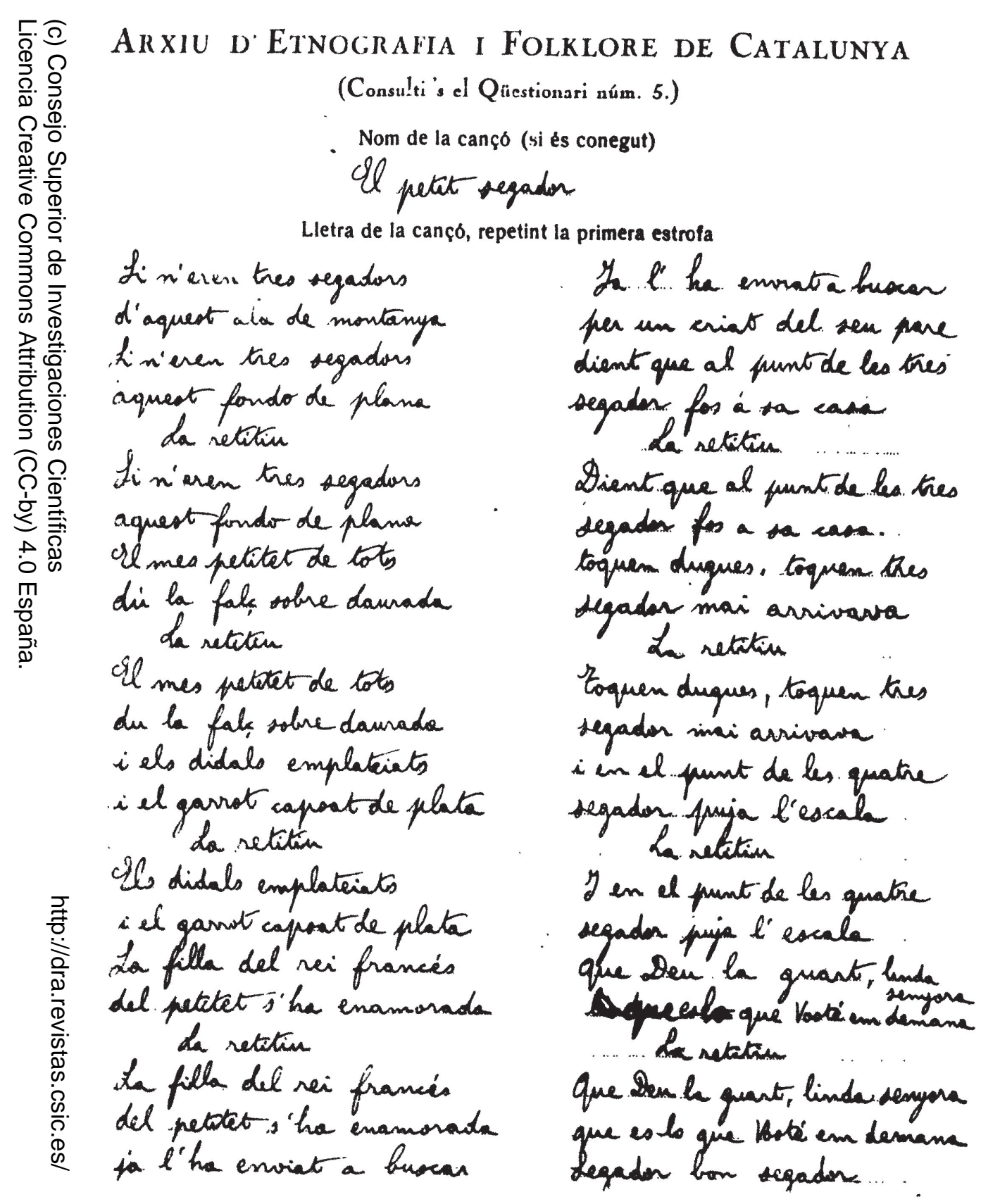


de los nuevos modos de trabajar ya los incorporó a su práctica etnográfica, como se puede apreciar en estas palabras de Batista i Roca:

L'experiencia ha ensenyat a l'A.d'E. i F. de Catalunya que per certs estudis especials, com investigació intensiva d'una área determinada, delimitació de fronteres entre varies árees etc., s'obtenen resultats molt millors i precisos afegint a les indicacions aportades pels col.laboradors, l'investigació sistematica de la regió en qüestió feta sobre ' 1 terreny mateix per membres de l'Arxiu.

L'aplicació d'aquest nou métode $s$ ' ha inaugurat durant el curs actual amb les investigacions fetes pel Secretari de l'Arxiu a la frontera dels dialectes catalans orientals i occidentals, obtenint-se molt bons resultats ${ }^{21}$.

Tal recurso metodológico se vio complementado con el método geográfico o cartográfico, herencia de lingüistas como Gilliéron o Griera, para la delimitación de los rasgos culturales.

Todos estos cambios en la forma de hacer Etnografía se pusieron al servicio de un fin último: la teoría de la Psicoetnografía. ¿Qué entendía Carreras por este concepto? Sencillamente, la investigación psicológica en base a los materiales etnográficos. Hasta tal punto éste fue el objetivo final de los trabajos de la institución que Batista i Roca situó el análisis de la psicología colectiva como la culminación de los trabajos de carácter antropológico. En 1918, antes de su marcha a Inglaterra, ya proclamó:

Si la Etnografia recull $\mathrm{i}$ estudia les manifestacions més espontànees i primitives de la cultura d'un poble, no cal gaire esforç per mostrar l'importància d'aquesta ciència per aportar materials en què fonamentar l'estudi de la Psicologia d'aquest poble $^{22}$.

El concepto de Psicoetnografía surgió en Carreras de las diversas influencias que al principio se han delineado. De forma gráfica, podría quedar así resumido:

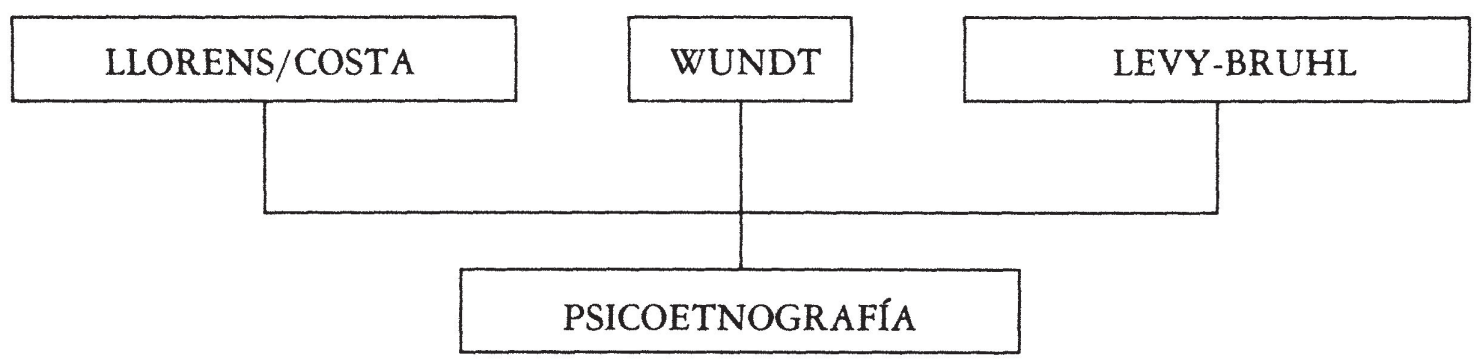

21 J. M.' BATISTA I ROCA, Informe sobre l'Arxiu d'Etnografia $i$ Folklore de Catalunya per el projectat Museu d'Etnografia de València, mecanografiado, inédito, pp. 2-3. Archivo AEFC. Este método de trabajo llevó al AEFC a recomendar que: «[...] cada col.laborador amb l'exprés intent d'aixugar-la [un área], al menys en ordre a la seva especialitat o peculiar afició.» Estudis i Materials, I (1916), pp. 107-108.

22 J. M.* BAtista I RocA, «Els materials etnogràfics i l'excursionisme», Excursions, 34 (1918), p. 102. 
N. d'entrada: 715 Lloc: SAMAL US Classificacio: A punt de dallar
(Vallés)

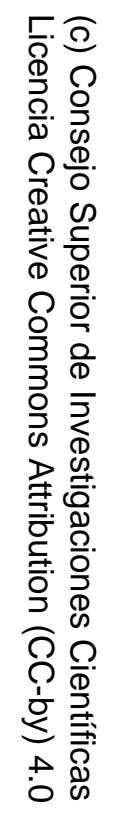

N. del elixe: I dem

Situacio:

coliector: $7 \cdot M \cdot B$. iR.

Data: Setembre 1921

Descripció La dalla us del tipus anomenat "dalla embridonada" o tia give lé un petit lirant de ferro (brido-) q ajuda a subjectar la fulla at màneg (El brido es a la confluencia de les dues linees picunteiades)

El dulticidor the subiecte ab una corretion a la cintusa, in recipient de fritu brisidadm, o. S'omple d'aigua i serveix pus tir. hi ba

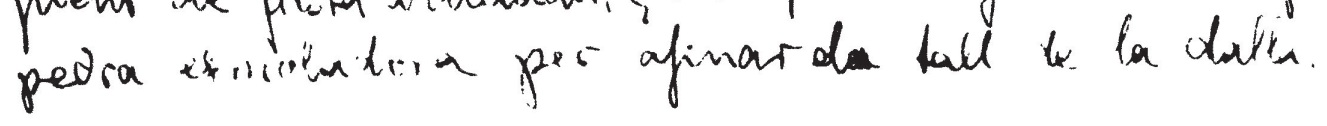

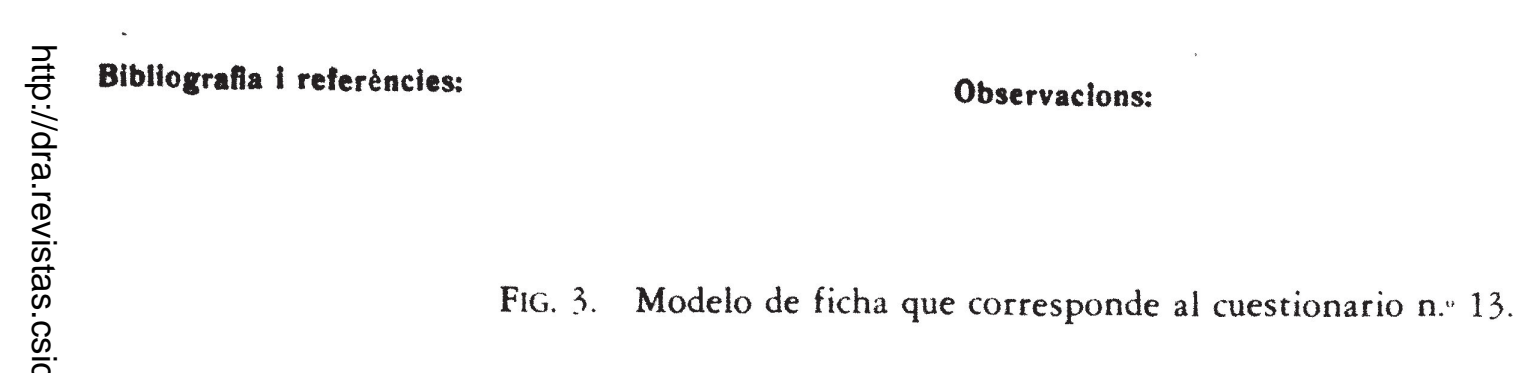


Estas influencias presentan un panorama sugestivo. Destaquemos tan sólo la de Lévy-Bruhl. Carreras rechazó la postura del científico francés con respecto a la división entre mentalidad primitiva y civilizada, prelógica y lógica. A pesar de esta diferencia, como dice Evans-Pritchard respecto a Lévy-Bruhl ${ }^{23}$, la preocupación de Carreras por la averiguación de los rasgos diferenciales de la mentalidad humana era tan sólo muestra de sus preocupaciones por la relación entre sociedad e individuo. Así, el planteamiento de Carreras está en la línea del estudioso francés, al reconocer la importancia del medio sociocultural como agente vital en la conformación de las actitudes y comportamientos de los individuos.

Este interés por las cuestiones de «cultura y personalidad» me da pie a señalar la fiabilidad que se produjo en el planteamiento y desarrollo de la Psicoetnografía. Hay que señalar, en primer lugar, que uno de los objetivo de Carreras al crear este modelo teórico y metodológico fue, al igual que el proyecto wundtiano, realizar una historia del psiquismo humano y analizar la mentalidad primitiva basándose en la comparación entre distintas mentalidades: hombre prehistórico, primitivo, rural y niño. Este tipo de comparaciones fue una práctica común a lo largo del siglo XIX, no obteniéndose resultados satisfactorios. Además, debe tenerse en cuenta que la misma teoría matriz, el proyecto wundtiano, se agotó en sí misma, ya que no logró crear un aparato teórico ni metodológico fiable para desarrollar las investigaciones. Su decadencia estuvo también provocada por los descubrimientos del Psicoanálisis, que sí logró crear un aparato teórico y metodológico para investigar e interpretar la psicología de los individuos ${ }^{24}$.

Asimismo, en aquellas primeras décadas del siglo, Boas ya aleccionaba a sus discípulos para que trabajasen en el campo de cultura y personalidad. Para ello recomendó estudiar concienzudamente un área determinada, no realizando excesivas generalizaciones o comparaciones. Consideraba que ésta era la única forma de llegar a la comprensión real de una cultura.

A pesar de los adelantos metodológicos y teóricos que supuso el AEFC para su tiempo, no logró formalizar su proyecto en términos similares a los conseguidos por la escuela de Cultura y Personalidad norteamericana, si exceptuamos el hecho de plantearse la investigación en áreas concretas. Además, la falta de construcción de un adecuado modelo etnográfico, la no visión de la relación individuo-sociedad, por ejemplo, en términos fun-

23 E. Evans-Pritchard, Historia del pensamiento antropológico (Madrid: Cátedra, 1987), p. 166.

24 Sobre la repercusión del Psicoanálisis en España, ver Th. F. GLICK, «El impacto del psicoanálisis en la psiquiatría española de entreguerras», José Manuel SánCHEz RoN (coord.), Ciencia y sociedad en España: de la Ilustración a la Guerra Civil (Madrid: Eds. El Arquero/CSIC, 1988), pp. 205-221. 
cionales, propició que las realizaciones adoleciesen de resultados plausibles, fiables.

Situaciones teóricas aliadas a las puramente circunstanciales (dictadura de Primo de Rivera, expolio durante la guerra civil) hicieron que el proyecto no llegase a buen término. Carreras volvió a intentar reactivar el proyecto pasada la contienda armada, mas la pormenorización de esta nueva tentativa queda fuera del ámbito del presente estudio.

Queremos señalar, finalmente, que la obra del Arxiu d'Etnografia $i$ Folklore de Catalunya adquiere relevancia de primer orden en el panorama de la historiografía etnológica hispana, ya que propicia nuevas perspectivas y orientaciones para la comprensión de la génesis y desarrollo de la Antropología catalana y española.

\author{
Luis Calvo Calvo \\ Institución «Milà i Fontanals» \\ (C.S.I.C. Barcelona)
}

El Arxiu d'Etnografia i Folklore de Catalunya es la primera tentativa de institucionalizar la investigación etnográfica en Cataluña, constituyéndose, asimismo, en una de las primeras de todo el país. Unido al Noucentisme catalán, receptor de la teoría etnológica europea del momento (Lévy-Bruhl, W. Schmidt, Marett, etc...), representó una transformación radical de lo realizado hasta el momento en el terreno de la Etnografía y el Folklore en Cataluña, cambio que se materializó en la teoría de la Psicoetnografía, creada por el director y fundador de la entidad, Tomàs Carreras i Artau.

Arxiu d'Etnografia i Folklore de Catalunya was the first attempt to institutionalise ethnographic research in Catalonia, becoming in the process one of the first to do so in Spain. Linked with Catalonian Noucentisme and deeply influenced by European ethnological theory of the time (Lévy-Bruhl, W. Schmidt, Marett et al), it represented a radical transformation from all that had been done up to then in the fields of ethnography and folklore in Catalonia. This transformation resulted in the theory of "Psychoethnography" created by the director and founder of the institution, Tomàs Carreras $i$ Artau. 